\title{
SCENARIO OF PAEDIATRIC OCULAR INJURIES
}

Prashant Singh ${ }^{1}$, Priyanka Sodani², Pushpa Varma ${ }^{3}$, Ulka Srivastava ${ }^{4}$

${ }^{1}$ Consultant Ophthalmologist, ASG Hospital, Bhopal.

${ }^{2}$ Assistant Professor, Department of Ophthalmology, GMC, Jammu.

${ }^{3} \mathrm{HOD}$, Department of Ophthalmology, Index Medical College, Indore.

${ }^{4}$ Director of Medical Education, Bhopal.

\section{ABSTRACT}

\section{BACKGROUND}

The proportion of paediatric ocular injuries as a cause of blindness has got a definite role to play in a developing country like India where poverty, illiteracy, lack of medical facilities, etc. are additional factors. The burden of eye trauma on societies is well documented.

The aim of this study is to evaluate the scenario of paediatric ocular injuries.

\section{MATERIALS AND METHODS}

The study was conducted in MGM Medical College and Associated MY Group of Hospitals, Indore; 65 patients of age group 0 - 15 years were selected from ophthalmic outdoor and indoor patients, emergency wards, paediatric wards and paediatric surgery ward of MY Hospital, Indore. A detailed history, comprehensive clinical examination and necessary investigations were done. Different types of treatment, which was needed in open and closed globe injuries were recorded. Patients were followed up for 3 6 months and best corrected visual acuity recorded.

\section{RESULT}

The overall proportion of ocular trauma in paediatric age group was 32.99\%; 72.38\% showed open globe injuries and close globe was $28 \%$. Wooden stick was the most common cause of injury; $53.84 \%$ were illiterates. In open globe injury, $60 \%$ patients had $\mathrm{BCVA} \leq 6 / 60$.

\section{CONCLUSION}

Maximum were open globe injury and overall prognosis of ocular injuries in children was poor.

\section{KEYWORDS}

Paediatric, Open/ Closed Globe Injuries, Poor Prognosis.

HOW TO CITE THIS ARTICLE: Singh P, Sodani P, Varma P, et al. Scenario of paediatric ocular injuries. J. Evolution Med. Dent. Sci. 2017;6(88):6099-6102, DOI: 10.14260/jemds/2017/1325

\section{BACKGROUND}

The proportion of paediatric ocular injuries as a cause of blindness has got a definite role to play in a developing country like India where poverty, illiteracy, lack of medical facilities, etc. are additional factors. The burden of eye trauma on societies is well documented.(1) The causes of paediatric ocular injuries are innumerable like bow and arrow made by broomsticks, thorns, twigs, knife, powdered colour, fire crackers, ball, stones and pencil.(2) Epidemiological studies help in planning of prevention and guide regarding management measures. ${ }^{(3)}$ The importance of eye trauma has increased because of the relatively high rate of trauma in paediatric age group. Various studies have reported that $20 \%$ - $50 \%$ of ocular injury admissions are children. $(4,5,6)$

Our study of ocular injuries in paediatric age group was specially undertaken to find out the common causes of injuries, their incidence and to evaluate the visual results after these injuries.

'Financial or Other Competing Interest': None.

Submission 03-08-2017, Peer Review 30-09-2017,

Acceptance 05-10-2017, Published 06-11-2017.

Corresponding Author:

Dr. Priyanka Sodani,

House No. 11, Sector-I,

Channi Himmat,

Jammu-180015, J \& $K$

E-mail:psodani@yahoo.com

DOI: $10.14260 /$ jemds $/ 2017 / 1325$

\section{MATERIALS AND METHODS}

The descriptive study was conducted on 65 cases of ocular injuries admitted and treated in ophthalmic wards and OPD, emergency department and paediatric surgery wards at MY Hospital, Indore, from September 2003 to September 2004.

An emergency surgical intervention was done for the management of ocular injuries and patients were admitted in eye wards for further treatment to prevent any infection. A standardised form was filled out for each patient documenting sociodemographic features, type of injury, traumatising agent, time of injury, symptoms, course of events and nature of first aid given and therapy received prior to presentation. The proportion of paediatric ocular injury was calculated amongst all the ocular injury cases reported during that period.

The type of injuries was defined as per the Birmingham Eye Trauma Terminology-

\begin{tabular}{|c|c|c|}
\hline Eye wall & $:$ & $\begin{array}{c}\text { Refers to rigid structures of cornea } \\
\text { and sclera }\end{array}$ \\
\hline $\begin{array}{c}\text { Closed-globe } \\
\text { injury }\end{array}$ & $:$ & $\begin{array}{c}\text { There is either no eye wall or } \\
\text { partial thickness wall (lamellar } \\
\text { laceration) injury }\end{array}$ \\
\hline $\begin{array}{c}\text { Open-globe } \\
\text { injury }\end{array}$ & $:$ & $\begin{array}{c}\text { There is through and through } \\
\text { wound of the eye wall, choroids and } \\
\text { retina may be intact/ prolapsed or } \\
\text { damaged. It is further classified as }\end{array}$ \\
\hline
\end{tabular}




\begin{tabular}{|c|l|c|}
\hline $\begin{array}{c}\text { Rupture of } \\
\text { the globe }\end{array}$ & $:$ & $\begin{array}{c}\text { rupture or laceration. } \\
\text { Occurs with blunt injury that } \\
\text { creates energy transmission over } \\
\text { large area leading to momentary } \\
\text { increase in intraocular pressure } \\
\text { and eye wall gives way to weakest } \\
\text { point. Rupture is an inside out } \\
\text { injury, so tissue termination is } \\
\text { substantial. }\end{array}$ \\
\hline Laceration & $:$ & $\begin{array}{c}\text { Is caused by a sharp object or } \\
\text { missile injury. It is further classified } \\
\text { as penetrating injury (POT), } \\
\text { intraocular foreign body (IOFB) and } \\
\text { perforating injury. }\end{array}$ \\
\hline Penetrating \\
injury
\end{tabular}

Every patient received detailed examination of oblique illumination (torch light) with magnifying loupe and slit lamp. Various other methods of examination were employed wherever patients were cooperative enough and felt necessary like distant direct ophthalmoscopy, direct ophthalmoscopy, indirect ophthalmoscopy, tonometry (Schiotz) and fluorescent staining. Few special investigations were performed wherever indicated like-

a. X-ray skull for IOFB and fracture AP and lateral view.

b. X-ray after application of limber ring for location of radio-opaque IOFB.

c. USG A and B Scan.

d. CT scan.

e. Fluorescein angiography.

After performing complete ocular and systemic examination, open globe injuries were taken in emergency for the tear repair under general anaesthesia. Corneal wounds were sutured using 10-0 monofilament nylon sutures as far posteriorly as possible.

All patients received at least 14 days of prophylactic IV Ciprofloxacin (dosage of $10 \mathrm{mg} / \mathrm{kg}$ body weight x 12 hourly) and metrogyl for 5 days (dosage $30 \mathrm{mg}$ x 8 hourly).

Topical Ciprofloxacin: 0.3\%, Betamethasone: $0.1 \%$ and Atropine: $1 \%$ were instilled after surgery. Oral prednisolone $(1 \mathrm{mg} / \mathrm{kg} /$ day) was administered in almost every case.

Any case suggestive of endophthalmitis during followup was immediately subjected to intravitreal injections of Vancomycin $1 \mathrm{mg} / 0.1 \mathrm{~mL}$ or Amikacin $0.4 \mathrm{mg} / 0.1 \mathrm{~mL}$.

All these cases were followed up for 3 - 6 months and if any complication occurred were managed accordingly.

\section{RESULTS}

In the study, the overall proportion of ocular trauma in paediatric age group was $32.99 \%$, i.e. in 65 cases out of 197 cases of total ocular injury cases reported to our referral centre in OPD and emergency ward.
Males were maximally involved in $4-6$ and $10-12$ years' age group. But as a whole 4 - 6 years' age group involved maximum cases, which were $29 \%$ - 33\% (Fig. 1).

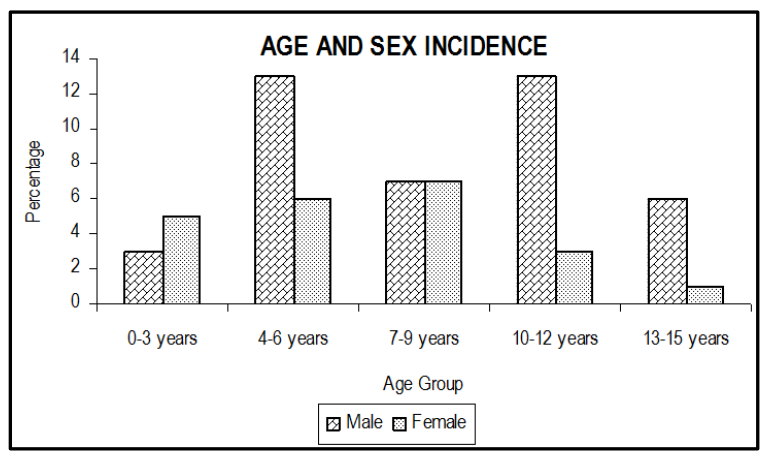

Figure 1. Age and Sex Incidence

About $3 / 4^{\text {th }}$ of cases, i.e. $72.38 \%$ showed open globe injuries as compared to close globe which was only $28 \%$ (Fig.2); 63 (96.92\%) cases were of mechanical injuries, whereas 1 case $(1.52 \%)$ each was of chemical burn and thermal burn (Fig. 3)

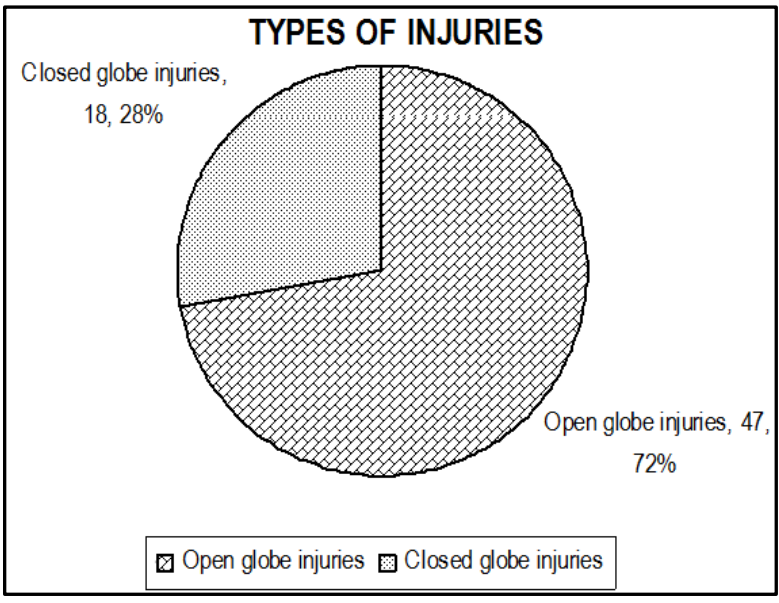

Figure 2. Types of Injuries

Wooden stick was found to be the most common cause of injury followed by iron objects and these when combined caused about $61 \%$ of injuries. Stone was responsible in 11 $(16.92 \%)$ cases. Glass piece, plastic objects, pen and pencils were responsible for 6 cases ( 2 each). Less common causes were ring, bow and arrow, lime burn, cow's tail, etc. (Fig. 3).

\begin{tabular}{|c|c|c|}
\hline Causes of Injuries & No. & $\%$ \\
\hline Wooden sticks & 21 & 32.30 \\
\hline Metallic objects & 19 & 29.23 \\
\hline Stone & 11 & 16.92 \\
\hline Glass piece & 2 & 3.07 \\
\hline Plastic objects & 2 & 3.07 \\
\hline Pen and pencil & 2 & 3.07 \\
\hline Ring & 1 & 1.53 \\
\hline Bow and arrow & 1 & 1.53 \\
\hline Lime burn & 1 & 1.53 \\
\hline Cow's tail & 1 & 1.53 \\
\hline By falling & 1 & 1.53 \\
\hline Agarbatti burn (Incense Stick) & 1 & 1.53 \\
\hline Nail & 1 & 1.53 \\
\hline Dust particles & 1 & 1.53 \\
\hline
\end{tabular}


Majority of the patients (53.84\%) belonged to illiterate people (as shown in the pie chart) (Fig. 4).

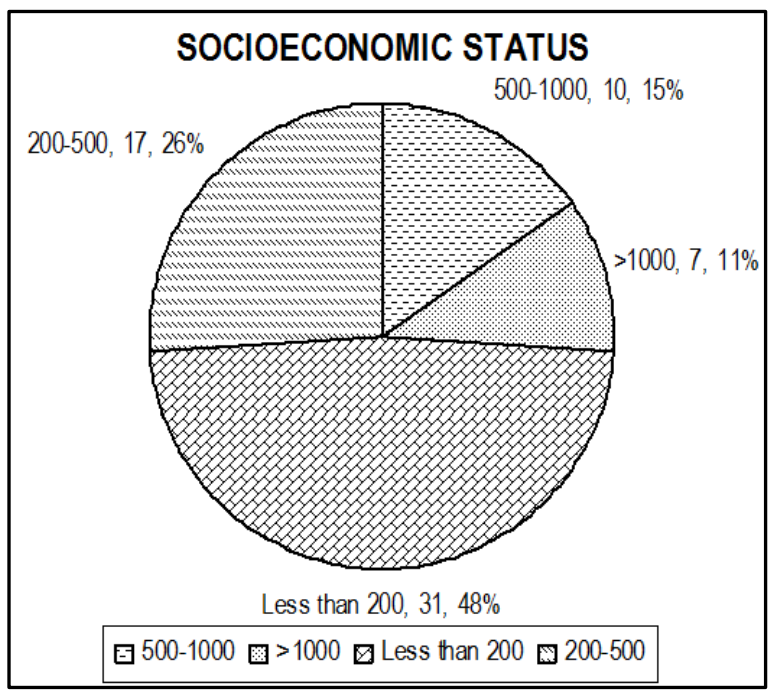

Figure 4. Socioeconomic Status

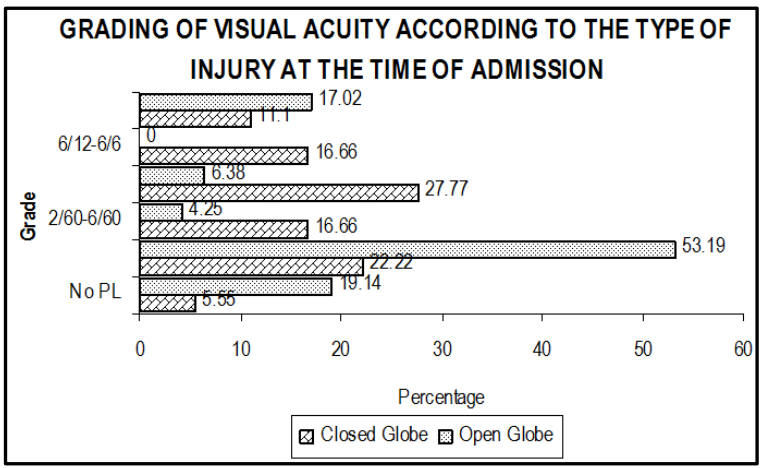

Figure 5. Grading of Visual Acuity according to the Type of Injury at the Time of Admission

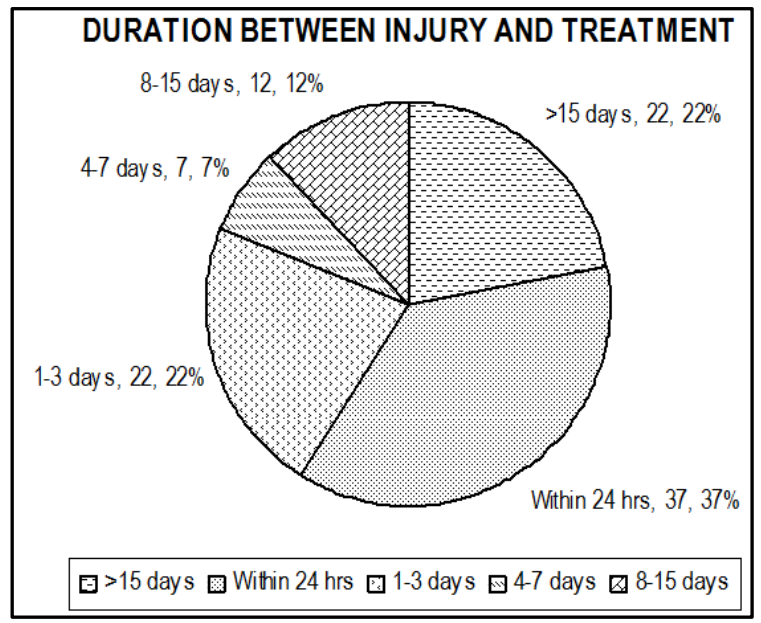

Figure 6. Duration between Injury and Treatment

At the time of first reporting in open globe type $72.33 \%$ cases had vision $<1 / 60$, whereas in closed globe type $83.09 \%$ had vision better than 2/60 (Fig. 5).

Best corrected visual acuity (BCVA) after followup of 3 - 6 months was $20 \%$, patients completely lost their vision; $50 \%$ of patients had BCVA $>6 / 12$ in closed globe injury and in open globe injury $60 \%$ patients had BCVA $\leq 6 / 60$.
Out of 65 cases 46 cases required surgical intervention and 16 cases were treated conservatively, whereas 2 required no treatment. Cornea was involved in $75.3 \%$ cases.

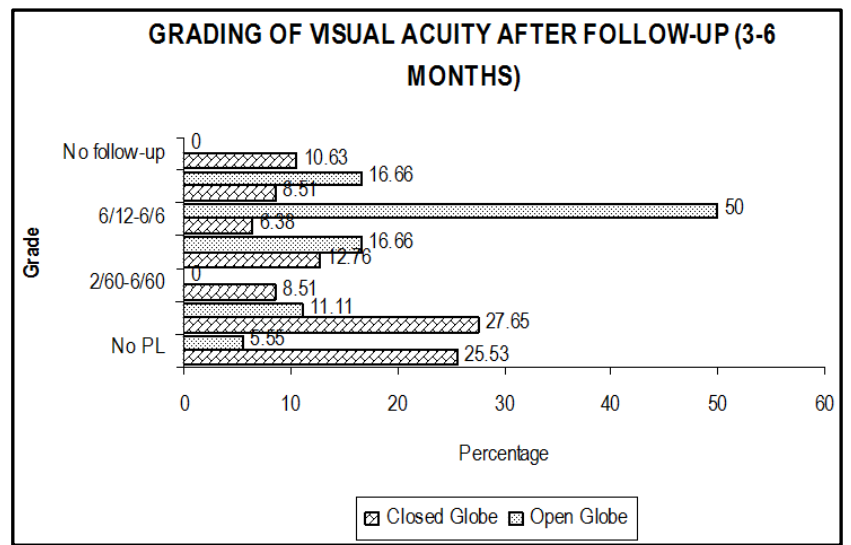

\section{Figure 7. Grading of Visual Acuity after Follow-Up (3 - 6 Months)}

In open globe injuries, $25 \%-53 \%$ became blind and $27.65 \%$ had visual acuity $<1 / 60$, whereas in closed globe injury visual acuity was $\geq 6 / 12$ in $66 \%$ cases (Fig. 7).

\section{DISCUSSION}

Injuries in paediatric age group are caused at home by unconventional play things (Fig. 4) as against injuries in adult age groups, which are mainly occupational and road traffic accidents. Paediatric injuries occurring most frequently at home has been stated in many studies also. $(4,7,8,9)$ Many of these injuries are preventable.(10) In our study, males were more commonly affected. $(2,8,11)$

Open globe injuries were more (Fig. 2) and had visual acuity $<1 / 60$ at presentation, which deteriorated further. The overall prognosis of ocular injury in children is considered poor in developing countries like India. The main reasons for this are lack of well-equipped eye care centres with round the clock facility for GA. Also as most rural areas do not have accessibility to an ophthalmologist, the patients have to travel large distances to urban centres before they can get proper medical treatment.

The type of injury and the extent of initial damage do affect the prognosis after penetrating injury,(12) but it has been documented that if early good anterior segment reconstruction which may involve removal of lens and iris with angle reconstruction IOL implantation and penetrating keratoplasty is done then results are highly satisfactory.(13)

\section{CONCLUSION}

There is a need for a better eye health care infrastructure with a special emphasis on paediatric trauma. With an increased awareness of the aetiology and circumstances surrounding childhood eye injuries, appropriately designed and targeted public health campaigns can be undertaken to avoid and prevent ocular trauma.

\section{REFERENCES}

[1] Al Wadeai EAY, Osman AA, Macky TA, et al. Epidemiological features of pediatric ocular trauma in Egypt. Journal of Ophthalmolgy Article ID 7874084, 2016;2016: p. 6. 
[2] Kaur A, Agrawal A. Paediatric ocular trauma. Curr Sci 2005;89(1):43-6.

[3] Negrel AD, Thylefors B. The global impact of eye injuries. Ophthalmic Epidemiol 1998;5(3):143-69.

[4] Thompson CG, Kumar N, Billson FA, et al. The aetiology of perforating ocular injuries in children. $\mathrm{Br} \mathrm{J}$ Ophthalmol 2002;86(8):920-2.

[5] Punnonen E. Epidemiological and social aspects of perforating eye injuries. Acta Ophthalmol 1989;67(5): 492-8.

[6] Moreira CA, Debert-Ribeiro M, Belfort R. Epidemiological study of eye injuries in Brazilian children. Arch Ophthalmol 1988;106(6):781-4.

[7] Dulal S, Ale JB, Sapkota YD. Profile of pediatric ocular trauma in mid-western hilly region of Nepal. Nepal J Ophthalmol 2012;4(1):134-7.

[8] Pardhi CH, Nandedkar VS, Shelke EB, et al. Pattern of pediatric ocular trauma in rural area of Marathwada. Journal of Clinical Ophthalmology and Research 2015;3(3):127-31.
[9] MacEwen CJ, Baines Ps, Desai P. Eye injuries in children: the current picture. $\mathrm{Br} \mathrm{J}$ Ophthalmol 1999;83(8):933-6.

[10] Nelson LB, Wilson TW, Jeffers JB. Eye injuries in childhood: demography, etiology and prevention. Pediatrics 1989;84(3):438-41.

[11] Desai T, Vyas C, Desai S, et al. Pattern of ocular injuries in paediatric population in western India. NHL J Med Sci 2013;2:37-40.

[12] De Juan E, Sternberg P, Michels RG. Penetrating ocular injuries. Types of injuries and visual results. Ophthalmology 1983;90(11):1318-22.

[13] Hersh PS, Kenyon KR. Anterior segment reconstruction following ocular trauma. Int Ophth Clin 1998;28:57-68. 